\title{
Authentic Literacy and Language (ALL) for Science: A Curriculum Framework to Incorporate Science-Specific Disciplinary Literacies into the Elementary Classroom
}

\author{
Nancy Moreno, $\mathrm{PhD}^{1,3}$, Alana Newell, $\mathrm{PhD}^{1,3}$, Misty Sailors, $\mathrm{PhD}^{2}$, and Dolores Garay, $\mathrm{MST}^{1}$ \\ ${ }^{1}$ Center for Educational Outreach, Baylor College of Medicine, Houston, Texas and ${ }^{2}$ College of Education, University of North Texas, Denton, Texas \\ ${ }^{3}$ Co-primary authors
}

Keywords: Science Teaching, Science Curriculum, Science Reading, Reading Strategies, Inquiry, Science Inquiry, Comprehension, Curriculum, Science Disciplinary Literacy, Elementary Science, NGSS, Life Cycles, Painted Lady Butterfly, Inherited Traits

Publication Date: November 10, 2020

DOI: https://doi.org/10.15695/jstem/v3i1.08

\begin{abstract}
Early elementary students are not typically introduced to science-specific disciplinary literacies - the specific ways in which scientists use and interpret language - even though authentic experiences with literacy strategies and tools used within the field may help incorporate learners into the scientific community of practice. The lack of freely available easy-to-use resources to build these literacies in the early elementary classroom may be a contributing factor. The Authentic Literacy and Language (ALL) for Science curriculum framework was developed as a deliberate approach to teach disciplinary literacies in the context of science using three distinct components: Science Investigations, Mini-lessons, and Science Inquiry Circles. Here we outline the development of the curriculum framework and a pilot of a $2^{\text {nd }}$ grade unit based on the framework to teach concepts related to heredity and life cycles. We present findings from the pilot and discuss future directions and implications for the development and implementation of curricular materials using the ALL for Science curriculum framework.
\end{abstract}

\section{INTRODUCTION}

Background. Students need science, technology, engineering and mathematics (STEM) knowledge and skills to be informed citizens and enter into a broad range of careers. However, many US students, especially those who come from economically disadvantaged or racially and ethnically marginalized communities, do not enter into or persist in STEM educational pathways (Hayes, 2017). There are a number of reasons students from these backgrounds may not pursue STEM disciplines, in general, or science, in particular. Some of the reasons include lack of access to high-quality educational experiences and mismatched or inadequate academic preparedness (Goldhaber et al., 2015; National Research Council, 2015). Additionally, even students who express interest and demonstrate academic achievement in science, may not persist because they view science as incompatible with their identities (Archer et al., 2010). Even in early elementary grades, students make distinctions between school science and success in school science, and the work of scientists in the real world, often viewing real science as isolated and unconnected with their lived experiences and identities (Carlone et al., 2014; Zhai et al., 2014). Thus, tra- ditional school science experiences may not be enough to help students view themselves as current or future members of the science community. Given that students' identities influence choice behaviors later in life, explicit connections to help students see themselves in science roles may be necessary to increase the number of underrepresented students choosing to enter STEM fields (Carlone et al., 2014; Vincent-Ruz, 2018; Zhai et al., 2014).

This perspective is reflected in the Next Generation Science Standards (NGSS). The NGSS expectations guide the immersion of students in science practices to deepen their science knowledge, while exposing them to authentic work processes, environments of STEM professionals and norms required to participate in the scientific community (National Research Council, 2012). Several of these practices and norms are related to the interpretation and communication of scientific information and ideas.

All scientists rely heavily on written texts, media and representations to learn from others, guide their work, express their ideas or findings and receive feedback from peers. They regularly engage in verbal discourse, formal presenta- 
tions and argumentation. Yet, reading, writing, speaking and listening in ways that are authentic to the practice of science are not part of most science curricula. Instead, students are expected to rely on general language skills to read textbooks, answer questions, or record and report any science investigations. Thus, students do not have opportunities to consume, produce, communicate, critique and engage in sense-making in ways that approach actual scientific practices (Pearson et al., 2010).

The specialized language-related skills that are typical of an academic discipline, such as science, fall within the domains of subject-specific disciplinary literacies, including the unique techniques, skills and tools used within a field to create and interpret text structures and features (Lee and Goldman, 2015; Shanahan and Shanahan, 2012). We refer to these specialized uses of language by scientists as science-specific literacies or disciplinary literacies for science. Disciplinary literacies for science are different from science or scientific literacy as normally understood by science educators. Science literacy refers to basic understanding of, 1) science practices, such as formulation and testing of hypotheses, 2) content knowledge consisting of facts, concepts and vocabulary and 3) understanding of science as a social process involving peer review, accumulation of accepted findings and venues for discussion and critique (National Academies of Sciences, 2016). Thus, disciplinary literacies for science deserve their own focus in a school curriculum and in daily instruction, in addition to the development of scientific literacy.

Elementary classroom teachers, however, typically use general or transcendent literacy strategies (those strategies that are associated with literacy across disciplines, and include strategies such as fix-up, word analysis, and summarizing, to name a few) instead of focusing on strategies that are typical of particular disciplines, such as science (Houseal et al., 2016). Understanding the various disciplinary literacy strategies is important because experts within disciplines interact with texts and text features in ways that are fundamental (and in some cases, unique) to the discipline (Shanahan et al., 2011). For example, expository science writing has unique features, such as difficult technical terms and other vocabulary, academic language (e.g., passive voice, complex phrase structures), and the extensive use of visual representations and symbols (e.g., graphs, charts, figures) that must be interpreted and compared to information found in the text (Buehl, 2017; Shanahan et al., 2011). Some of these features can be found in texts from other disciplines, but their interpretation and uses may be different. For example, while historical and scientific texts both include graphical text features, there are differences in how the fields view the features in reference to the text. Scientists often view graphics as equally important to the text itself, delivering infor- mation that overlaps with the text, whereas historians may view graphical features as subordinate supporting evidence (Shanahan et al., 2011).

Understanding the way scientists make meaning of discipline-related texts can help students learn to make meaning of the science itself, while practicing sense-making skills that are applicable to literacy in general (Pearson et al., 2010). Despite the benefits, however, of developing and enhancing students' science-specific disciplinary literacies, teachers frequently have difficulty integrating this type of instruction into their classrooms. The challenges may be due to their own difficulties with understanding the literacy practices specific to science, concerns about overshadowing science inquiry with a text-centric approach, or lack of well-designed texts at appropriate reading levels (Pearson et al., 2010), to name a few.

For elementary students, few programs directly (or indirectly) address development of disciplinary literacies in the context of science. Seeds of Science/Roots of Reading from Lawrence Hall of Science is an example of an evaluated and commercially available $2^{\text {nd }}-5^{\text {th }}$ grade curriculum that integrates inquiry-based science instruction and development of disciplinary literacies for science through first hand investigations and nonfiction books developed for use with each unit (NRC, 2014). The curriculum engages students in four basic language elements - Do-It, Talk-It, Read-It, Write-Itas they engage in first- and secondhand investigations. And, while we appreciate the complexity of the program and the way it integrates reading and writing with authentic science experiences (Cervetti et al., 2012), we sought to develop a freely available program that would include students in a legitimate community of practice that mirrors typical practices of scientists.

Accordingly, we set out to develop and pilot an easily implemented approach to teaching science-specific disciplinary literacy - in the context of grade-level appropriate science inquiry and English language arts (ELA) strategies. The resulting curriculum framework, Authentic Literacy and Language (ALL) for Science, engages students in three different ways each day: (a) firsthand science inquiry activities (Science Investigations) aligned to Next Generation Science Standards (NGSS Lead States, 2013); (b) reading and writing strategy Mini Lessons focused on science-specific disciplinary literacies; and (c) small group collaborative textbased research (Science Inquiry Circles) aligned to Common Core State Standards Initiative (CCSSI, 2020).

Through the curriculum framework and resulting unit, we also sought to increase students' science content knowledge and science skills as we folded students into the community of practice of scientists. In this paper, we provide an overview of related work that guided our efforts, introduce the curriculum framework, and describe the preliminary outcomes from our pilot second grade study. 
Communities of Practice: Learning to Read, Write, and Think Like a Scientist. There is a growing movement in education to align development work (curriculum and instruction) to contemporary learning theories. For our current project, we situated our work within sociocultural learning theories. Arising as a family of theories, sociocultural theories build on the work of Lev Vygotsky and subsequently they share many of the same assumptions about the mind, the world, and the relationship between the two (Gavelek and Bresnahan, 2009). Minds of individuals (including their knowledge, behaviors, attitudes, morals, and values, etc.) develop within a social context and not individually as earlier learning theories would suggest. For educators, this means that learning must be a social process - one that is governed by many and ongoing interactions between teachers and children, and children and children. The nature of those interactions must be mediated by materials and language.

While there are many tenets to their theory, we grounded the development of ALL for Science on Lave and Wenger's notion of how newcomers (or novices) become established members of a community of practice. Lave and Wenger (1991) found that newcomers spend time initially observing and performing simple tasks and basic roles as they learn how the group works and what their contribution can be. But their identities can only be built if they interact with existing members (or "experts"), are mentored by the experts, and have access to archived materials produced by the experts.

"Science" is one such domain and the members of that community of practice, commonly called scientists, are the constituent members of the community. Although there are many sub-communities within the field of science, there is a general domain (scientific knowledge); a shared way of "being" as a scientist; and a specific focus that the community creates, shares and preserves its knowledge, i.e., its practice. From a community of practice perspective, learning science is about embodying the discourse of science - the language, thinking, believing, feeling, valuing, and acting that are characteristic of scientists. As summarized in the Framework for K-12 Science Education, "scientists constitute a community whose members work together to build a body of evidence and devise and test theories" (NRC, 2012, p 27).

The question, then, becomes, how do children and youth develop proficiencies needed to engage in science inquiry, including how to read, write, and reason with the language, texts, and dispositions of science? (Pearson et al., 2010, p. 459). In other words, how do we create spaces in classrooms where children are "folded into" the practice of science, where they learn the language of science and the dispositions and attitudes that lead them to a life-long practice as a scientist (as a career) and/or a way of looking at life and phenomena through the eyes of a scientist? Furthermore, how do we do this in a way that recognizes and builds on the experiences and growing understanding children bring to the classroom about the natural world around them? Rather than presenting academic language as dichotomous to the home language of children and the lived experiences of children, we see the teacher as playing a critical role in helping children make connections between the two (Flores, 2020). That is, rather than create a curriculum framework that portrays children from the communities in which our work took place as deficit in their knowledge about science, science concepts, and science-specific disciplinary literacies, we wanted to create a curriculum framework that builds on the vast interest and language expertise children bring to the classroom with them.

This is what we set out to do with the ALL for Science program: design and develop a curricular approach that teachers could use to create a community of practice in their classroom and bring newcomers into the practice of science. The resulting approach focuses, in particular, on authentic and intentional aspects of 1) group participation, 2) practices of scientists (including language and tools), and 3) developing students' skills to use archived expert materials (including multimedia and text-based materials).

In the next section, we describe the design process and the curriculum framework.

Curriculum Framework. Development of the ALL for Science curriculum framework began with meetings of the project curriculum design team in spring 2016. The 12-member team consisted of elementary teachers, district-wide curriculum specialists, scientists, science educators, and experts in disciplinary literacies. Importantly, the team was balanced to include science and English language arts (ELA) content experts, educators in each of the two content areas, and classroom teachers.

We applied backwards design methods (Wiggins and McTighe, 2005) to brainstorm the overall approach to instruction and develop learning outcomes for the first unit described here. All members of the design team received pre-reading materials on backwards curriculum design and science teaching for early elementary grades (Ashbrook, 2016; Edson, 2013). The team members worked in small groups to develop outcomes, proposed assessments and teaching activities that would integrate science, reading, writing, speaking and listening seamlessly for students.

The design team agreed that the final curriculum resources should include: 1) a focus on real-world applications and practices of science; 2) a range of English Language Arts (ELA) strategies, especially those important for reading, writing and discourse in the context of science; 3) strategies to build awareness of the roles of scientists, engineers and health professionals, and the career opportunities that exist in science and related fields; and 4) reflection of recommendations of the Next Generation Science Standards - with particular emphasis on guiding student sense-making through 
direct observation of phenomena and use of informational text and resources (NGSS Lead States, 2013; EQuIP Rubric, 2016).

As envisioned by the design team, the teaching materials should be easy to use from a teacher's perspective and reflect how scientists conduct investigations, communicate and interact with text resources. Students would carry out their own guided science investigations - and learn and apply transcendent and science-specific literacy strategies for text-based research. In other words, they would develop disciplinary literacies for science. In this context, transcendent literacies refer to generic strategies for reading, writing, speaking and listening that apply to a range of contexts, such as using text features to locate key information or participating in collaborative conversations by linking students' own comments to those of others (CCSSI, 2020). Science-specific literacies, for example, include strategies for verbal or written discourse and using or interpreting tables and graphs that represent experimental data.

The focus on science-specific disciplinary literacies would then facilitate legitimate peripheral participation by students in a classroom-based scientific community of practice - which mirrors scientific communities of practice in the real world. Legitimate peripheral participation refers to how newcomers learn within a social context, become integrated into a community of practice, and form identities as members of the community (Lave and Wenger, 1991), an identity that does not ask them to negate the one that they bring to the classroom with them (Flores, 2020).

The resulting curriculum framework relies on three components to meet the design principles established by the design team.

- Science Investigations - Firsthand science inquiry activities, in which the teacher facilitates students' collaborative work related to a model organism or system to build understanding of core ideas and crosscutting concepts in science (such as patterns or cause and effect);

- Reading Mini-lessons - Whole group mini-lessons that focuses on a reading strategy relevant for use with science expository texts or media; and

- Science Inquiry Circles - Small groups, similar to reading circles, in which learners apply and practice discipline specific reading strategies to their own textbased research.

During the Science Investigation activities, groups conduct guided inquiry activities in which their data sources are direct observations of natural systems. Students engage in data collection using authentic science tools and analyze their evidence to answer central questions that span several days or weeks. The ALL for Science framework asks stu- dents to take on roles that reflect authentic positions held by members of scientific teams (lab director, data scientist, lead scientist, and equipment director) - instead of using typical classroom science job assignments, such as principal investigator, recorder/reporter, materials manager and maintenance director.

The Science Investigation component is complemented by guided, small group, text-based work oriented around what we call Science Inquiry Circles. Within the Science Inquiry Circles, each group identifies and explores a research question of their choosing using existing grade level-appropriate expository text resources accessible through the school district to gather information and draw conclusions from evidence. The Science Inquiry Circle questions are related to the core ideas of the overarching science investigation and are intended to expand students' knowledge in ways that are similar to how scientists might use published resources to inform and extend their own findings from laboratory or field investigations. The text resources are compiled and reviewed in advance, so that students select from scientifically accurate and appropriate sources for their textbased research.

Students are supported by daily science-specific disciplinary literacy mini-lessons aligned with English Language Arts (ELA) standards, designed to help them apply the literacy skills in science specific ways (e.g., drawing conclusions, summarizing, finding the main idea). The practices are modeled by the teacher using appropriate expository text and summarized in anchor charts co-created by the teacher and students for display in the classroom.

The connections across the three components and intended student outcomes are depicted in the curriculum framework logic model (Figure 1).

Pilot Unit. In order to examine feasibility and effectiveness of the curriculum framework, we developed a three-weeklong unit on animal life cycles and inheritance to implement in second grade classrooms; we called this unit Heredity and Life Cycles. We selected second grade to pilot the framework, so that we could examine its effectiveness prior to implementation in challenging first grade environments, in which there is more variance in student general literacy, or third grade, in which high-stakes testing puts additional pressure on classroom teachers. Statewide and local student performance on standardized tests items pointed to a need for additional teaching materials on these topics for the early elementary grades. In general, the unit was developed to address NGSS disciplinary core ideas for life science, while also reflecting cross-cutting concepts (such as patterns or structure and function), and science and engineering practices. Since the field test was planned for the State of Texas, the unit was contextualized to align with requirements for second grade science. 


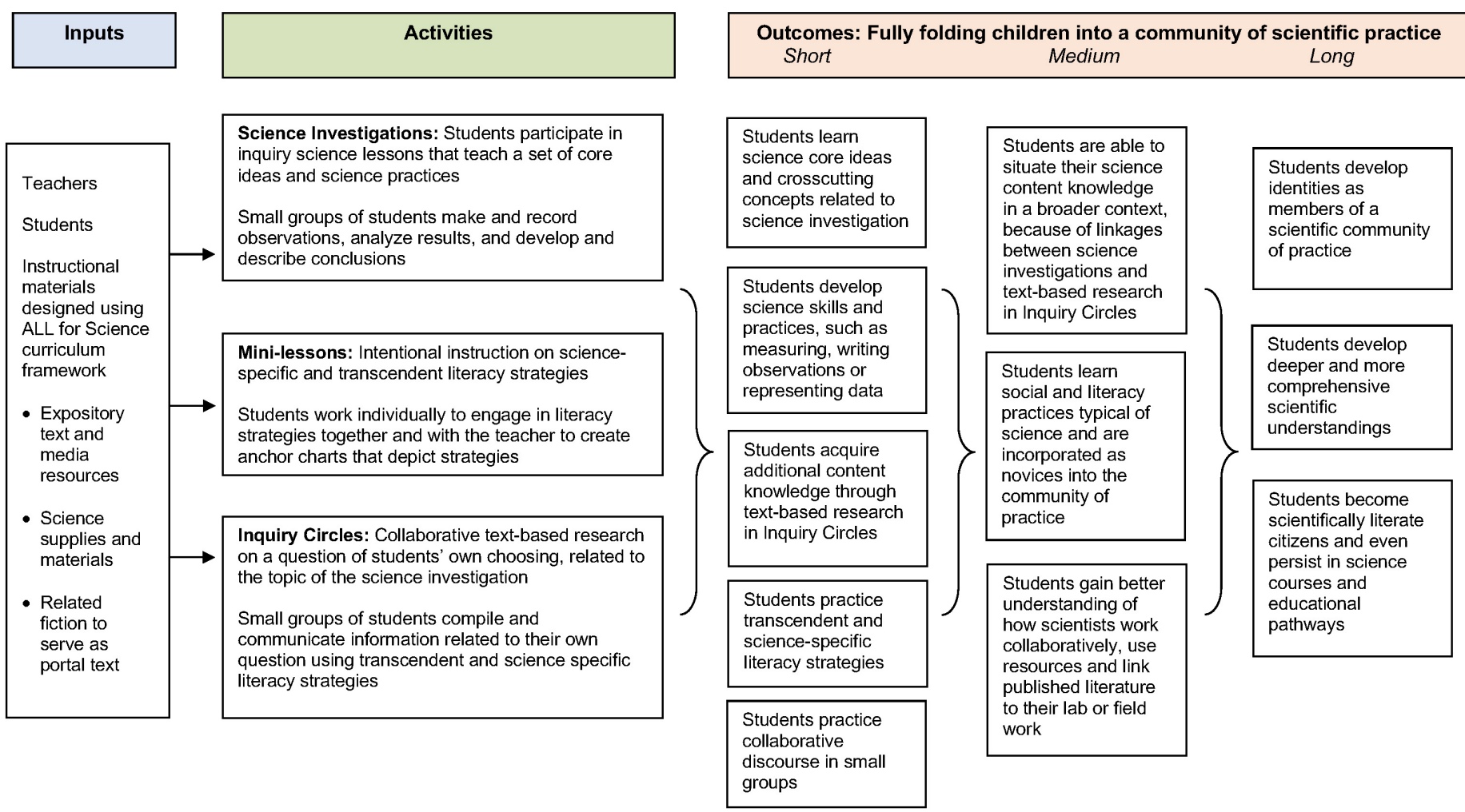

Figure 1. Authentic Literacy and Language (ALL) for Science Curriculum Framework Logic Model

As part of the process, the learning outcomes were aligned so that explicit connections could be made between science sense-making and language sense-making. The guided Science Investigation aspect of the unit focused on the life cycle of the painted lady butterfly. These activities were teacher-guided, but students conducted the activities within small groups. Students engaged in daily activities related to the butterflies, as they observed (and recorded) a portion of the life cycle (beginning with larvae) over three weeks. In addition to observing one organism (painted lady butterfly) closely firsthand, they built upon what they were learning through direct observation and data gathering by conducting text-based research on the organism-following a process analogous to how a scientist might consult the published literature to inform work with a model organism or system on a daily basis.

Simultaneously, within the Science Inquiry Circles, each student group expanded their knowledge about life cycles by collecting information about the life cycle of a different animal or insect using pre-screened expository texts and other media. The members of each Science Inquiry Circle were expected to compile their findings as a team in the form of a capstone presentation. Each Science Inquiry Circle group selected a different organism to investigate from a menu of options (penguin, salamander, sea turtle, spider monkey, butterfly). The menu was created during the curriculum design phase and consisted of organisms with different kinds of life cycles for which there were adequate available resources (print and online books, video and other media, websites, etc.) at the appropriate reading levels for students. The information was provided to teachers as a spreadsheet with URL links. Teachers also were encouraged to access any other available resources within their schools or school districts, including both hard copy and digital texts.

Our intent was to fully align all curricular components on each day. In practice, this was not possible, because the reading mini-lessons focused on a range of science-specific or useful transcendent literacy strategies, which were not always connected directly to the Science Investigation. Day 11 is an example of alignment across the various curriculum components. In the Science Investigation, students completed observing images of wing patterns of parent and offspring butterflies and reached conclusions about patterns of inheritance. For the ELA portion of the day, they learned strategies for drawing conclusions based on information that they have read, and began summarizing the information on the organism that they had been working on in their Science Inquiry Circles. On other days, the various activities were complementary, but parallel. For example, on Day 5, students mapped the movements of butterfly larvae in clear habitats, learned a reading strategy called "skimming and scanning" for locating specific information within a text and continued their text-based research on the life cycle of their selected organism. The full unit description is depicted in Table A in the Appendix. 


\section{METHODS}

To examine the effectiveness of the ALL for Science curriculum framework as implemented in the Heredity and Life Cycles second grade unit as well as the unit itself, we piloted the materials and collected quantitative and qualitative data from both teachers and students. Our goals in doing so were to 1) garner actionable feedback from experienced teachers with a demonstrated commitment to science and science instruction, and 2) obtain evidence regarding curriculum success in meeting student learning outcomes, so that we might improve the curriculum framework and specific unit prior to broader dissemination. The evaluation questions that guided this process are: 1) Is the framework logistically feasible to implement in elementary classrooms?; 2) To what extent can teachers implement the ALL for Science framework, in the context of the Heredity and Life Cycles unit in a grade-level appropriate, effective way?; and 3) Is a unit built upon the framework effective in enhancing student knowledge, strategies and skills as outlined in the desired short term program outcomes?

Pilot Procedures. We piloted the Heredity and Life Cycles unit with 18 teachers and approximately 350 students from two large, urban school districts during spring 2018. Teachers were recruited via email invitations with a call for applications. Teachers were selected for participation based on years of science and English Language Arts (ELA) teaching experience to ensure they would be sufficiently experienced in both content areas to provide constructive feedback. We did not, however, screen teachers to identify the science or general literacy strategies that they typically used. Teachers reported that the majority of participants - all students in their classrooms - were Hispanic, English Language Learners, and at/below grade level in both science and ELA (Table 1).

Participating teachers attended an orientation where they were introduced to the concepts of disciplinary literacies and scientific communities of practice, and given an overview of how the unit was organized. They received all materials needed to teach the lessons, including butterfly larvae which were shipped from the supplier to coincide with timing of classroom activities. Participants were asked to implement the lessons over 15 consecutive classroom days at any time during a 6-week-long pilot program period. For the evaluation component, they were tasked with providing daily feedback on various aspects of the curriculum framework and content of the unit, completing a holistic post-evaluation, and collecting de-identified student data. Each teacher was given a notebook containing a complete detailed plan for each day's activities and all necessary classroom materials, student assessments and printed handouts; all resources also were available online on a private website. The teachers received a stipend for participating in the pilot.
Table 1. Teacher reported demographic characteristics of all participating students $(N=375)$.

\begin{tabular}{|c|c|c|}
\hline Demographic Category & & $\%$ \\
\hline \multicolumn{3}{|l|}{ Race/Ethnicity } \\
\hline & Asian & 3.95 \\
\hline & African-American & 19.57 \\
\hline & Hispanic & 66.37 \\
\hline & White & 8.43 \\
\hline & Other & 1.68 \\
\hline \multicolumn{3}{|l|}{ Gender } \\
\hline & Male & 50.67 \\
\hline & Female & 49.33 \\
\hline \multicolumn{3}{|c|}{ English Language Learners } \\
\hline & & 34.13 \\
\hline \multicolumn{3}{|l|}{ Science Achievement } \\
\hline & Above grade level & 23.69 \\
\hline & At grade level & 40.98 \\
\hline & Below grade level & 35.43 \\
\hline \multicolumn{3}{|c|}{ English Language Arts (ELA) Achievement } \\
\hline & Above grade level & 18.37 \\
\hline & At grade level & 38.79 \\
\hline & Below grade level & 42.85 \\
\hline
\end{tabular}

\section{Evaluation Instruments.}

Daily Evaluations. Each day, teachers provided feedback on ease of implementation and aspects of both the framework and unit that were effective with their students. Specifically, we asked teachers to report: 1) amount of time allocated to each component of the framework (Science Investigation, Mini-Lesson, Science Inquiry Circle) on that lesson day; 2) ratings on Likert-type items about appropriateness of the framework, effectiveness of that day's approach in teaching the ELA and science content, and perceptions about students' Science Inquiry Circle participation; and 3) written feedback about what they liked and disliked about that day's lessons, any changes made to written materials (e.g., organization, content), and their students' successes and struggles.

Teacher Post-Evaluation. At the conclusion of the pilot, we asked teachers to complete a post-evaluation to gather feedback on both the curriculum framework and the Heredity and Life Cycles unit. The post-evaluation asked teachers to provide: 1) additional demographic information for themselves and their students; 2) Likert-type ratings related to the framework (e.g., ease of implementation of the three components, cohesiveness of daily lessons, effectiveness of individual components in helping students learn content); 3) Likert-type ratings related to perceptions of student outcomes (e.g., changes in specific student ELA and science strategies and skills, ability of students to engage in Science Inquiry Circle work); 4) Likert-type ratings of their overall perceptions about the framework (e.g., organization, teach- 
ability, likelihood of using such an approach in the future); and 5) written comments with specific feedback on strengths and weaknesses of the framework and the individual lessons (e.g., what worked well, what should be removed).

Student Content Knowledge Tests. Student learning outcomes were assessed with a 24 -item pre- and posttest (Cronbach's $\alpha$ pre- $\alpha=.71$ ) developed by the curriculum development team to encompass ELA, science content, skills and vocabulary, and science-specific disciplinary literacy content (see appendix for copy of instrument) aligned with state standards for second grade. The assessments were administered prior to beginning the activities and again immediately following completion of the unit.

Student Written Reflections. Each week, teachers asked their students to complete independent written responses to the same text-based prompt about the ways in which they "were a scientist" and the reading strategies they applied that week. Analysis of the student weekly writing assignments - for evidence of content understanding, engagement in scientific practices and science-specific usage of language - is ongoing and not reported here.

Analyses. We examined teacher Likert-type ratings both visually and using descriptive statistics to identify and explore differences across individual lesson days and classrooms. Open-ended comments were reviewed and coded using thematic analyses. Student pre and post-content test data were analyzed first with a paired t-test to ascertain whether content knowledge, on average, increased from pre- to posttest. Next, individual items were evaluated visually and with descriptive statistics in order to investigate areas of weakness or systematic differences between types of classrooms related to content knowledge. This was particularly important as we wanted to ensure effectiveness of the materials for all classrooms, including those with high proportions of below average readers or English Language Learner (ELL) students. We also conducted a post-hoc evaluation of items related to inherited traits concepts to better understand teacher qualitative feedback.

Post-hoc Investigation of Alignment with National Standards. To inform future modifications and use of the curriculum framework, the Heredity and Life Cycles unit retrospectively was examined for alignment with recommendations of the Next Generation Science Standards using the EQuIP Rubric for Lessons and Units: Science (EQuIP Rubric, 2016). The EQuIP Rubric enables criterion-based review of lessons or units and informs development of new teaching resources. For this project, an experienced educator and curriculum designer who was not involved with the development of the pilot unit, examined the materials and rated the evidence of quality for each item under the three rubric categories - Three Dimensional Design, Instructional Supports and Monitoring Student Progress. The rubric became available while we were developing the unit, so it was not taken into consideration until after the unit had been piloted.

\section{INITIAL FINDINGS}

Feasibility in Elementary Classrooms. Overall, teachers participating in the pilot reviewed the ALL for Science curriculum framework as presented in the Heredity and Life Cycles unit favorably. Using a five-point scale, on the post-evaluation, 14 of the 18 teachers indicated that, overall, they "liked" or "loved" the ALL for Science curriculum framework, while the other four rated their feelings as neutral. The majority of teachers also indicated that implementation of the framework components (i.e., the sequence of hands-on, guided Science Investigations, science-specific disciplinary literacy Mini-lessons, and Science Inquiry Circles) proceeded smoothly, the framework approach was effective in helping their students learn both reading and science, and that students were able to apply the science and reading skills within the Science Inquiry Circle component of the unit (Figure 2).

Participating teachers' open-ended explanations of their ratings for the ALL for Science framework generally were positive, with 10 of the teachers commenting that they would use the framework as outlined.
I loved the model and I think that I will use this approach again in the future. It was engaging and hands on. - Teacher $\mathrm{K}$
I would definitely like to use this model or similar kind of models as a part of my instruction as it has rigor, differentiation, reading strategies, vocabu- lary, visual and kinesthetic learning. My students could work as scientists, have real world experience of challenges faced by butterflies during migration, improve their reading skills, and internalize new vo- cabulary. - Teacher Q

Three of the teachers commented that they would use parts of the lessons, but would change or omit portions of the framework itself.

I would use the science content part of this lesson. The small groups yes, but the research would be hard for me on a day to day lesson. - Teacher $\mathrm{H}$

Two teachers felt that the framework was not appropriate for the grade level.

The model will be more suited to a higher level class possibly third or fourth grade but not second grade. 


\section{Overall, I liked the model of instruction.}

\section{Overall, implementation of the model of instruction was smooth.}

\section{Transitions between the different aspects of the model of instruction were smooth.}

\section{Overall, the set of activities in the model of instruction} were aligned and cohesive.

The model of instruction was effective in helping my students learn the SCIENCE CONTENT.

The model of instruction was effective in helping my students learn the READING STRATEGIES.

\section{Overall, my students were able to apply the WHOLE} GROUP SCIENCE content to their inquiry circle work.

Overall, my students were able to apply the READING MINI-LESSON strategies to their inquiry circle work.

\section{ఐ Strongly disagree $\square$ Disagree} tions, Mini-lesson, Science Inquiry Circles).

The students in my class are still struggling with flu-

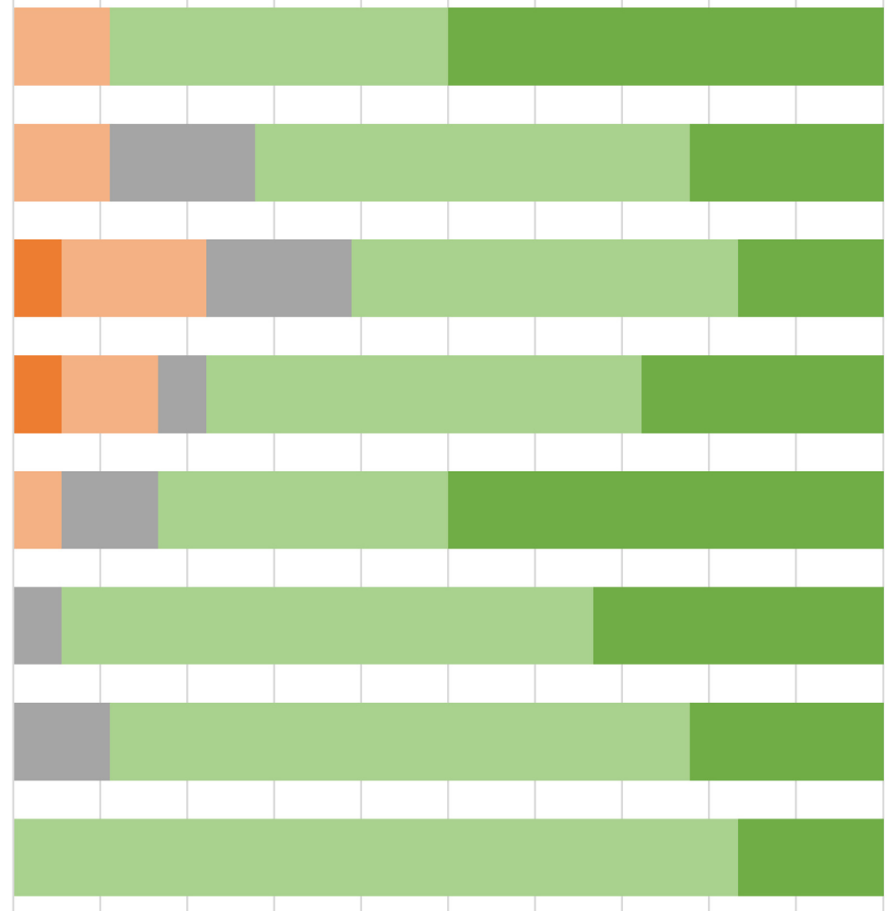

$\begin{array}{lllllllllll}0 \% & 10 \% & 20 \% & 30 \% & 40 \% & 50 \% & 60 \% & 70 \% & 80 \% & 90 \% & 100 \%\end{array}$

\section{$\square$ Neither $\quad$ Agree $\quad$ Strongly agree}

Figure 2. Percentage of pilot teachers giving each rating to various aspects of the ALL for Science Model (i.e., Science Investigaency and comprehension. - Teacher L

The final two teachers had differing concerns. One teacher felt that the timing of the reading instruction was not aligned with when the district usually includes general literacy strategy instruction as part of reading/English language arts, and the other felt that the framework would not support an entire year given the number of different kinds of texts (e.g., fiction) students are required to read.

When asked to share positives and negatives of the overall experience, three teachers provided comments that were related to difficulties with the framework and organization of the components. Of these, two teachers had difficulties with classroom management of small group work, and one teacher felt that the connections across framework components were not explicit enough.

Implementation of the Framework in the Heredity and Life Cycles Unit.

Teacher Feedback on the Unit. After completion of each activity day, teachers were asked to indicate their level of agreement on a 5-point scale to several statements related to the appropriateness and effectiveness of the ALL for Science framework for that day's Heredity and Life Cycles activities. For all 15 days of lessons, the majority of teachers either agreed or strongly agreed that the framework was appropri- ate for their classrooms and effective for teaching the days' ELA and science content to their students (Figure 3). The two-part Butterfly Offspring activity on days 14 and 15 received the lowest levels of agreement for appropriateness $(64.7 \%$ and $62.5 \%)$, with four teachers on day 14 and two on day 15 indicating that they disagreed or were neutral in regards to the statement that the activities were appropriate for their students on those days. Specifically, teachers indicated that the concepts or vocabulary related to phenotype, genotype, and dominant and recessive traits were too difficult for their learners.

The activity days that were considered least effective differed from those with the lowest appropriateness ratings: the lowest levels of agreement with the statement related to activity effectiveness were on day 11 (64.7\%) and days 1, 7 and 10 (all 70.6\%). Teacher explanations for disagreement or neutral ratings indicated that such ratings on Day 7 were due to the absence of a whole group Science Investigation for that day ( 3 of 4 comments). For the other three days, the most frequent feedback from teachers was related to the difficulty level of science vocabulary or concepts (4 of 11 comments), and perceived lack of alignment among the framework components ( 3 of 11 comments; Figure 3).

Teachers were asked to rate their student's ability to apply each day's hands-on Science Investigation lesson information to their small group Science Inquiry Circle work, and once again, the majority of teachers agreed or strongly 


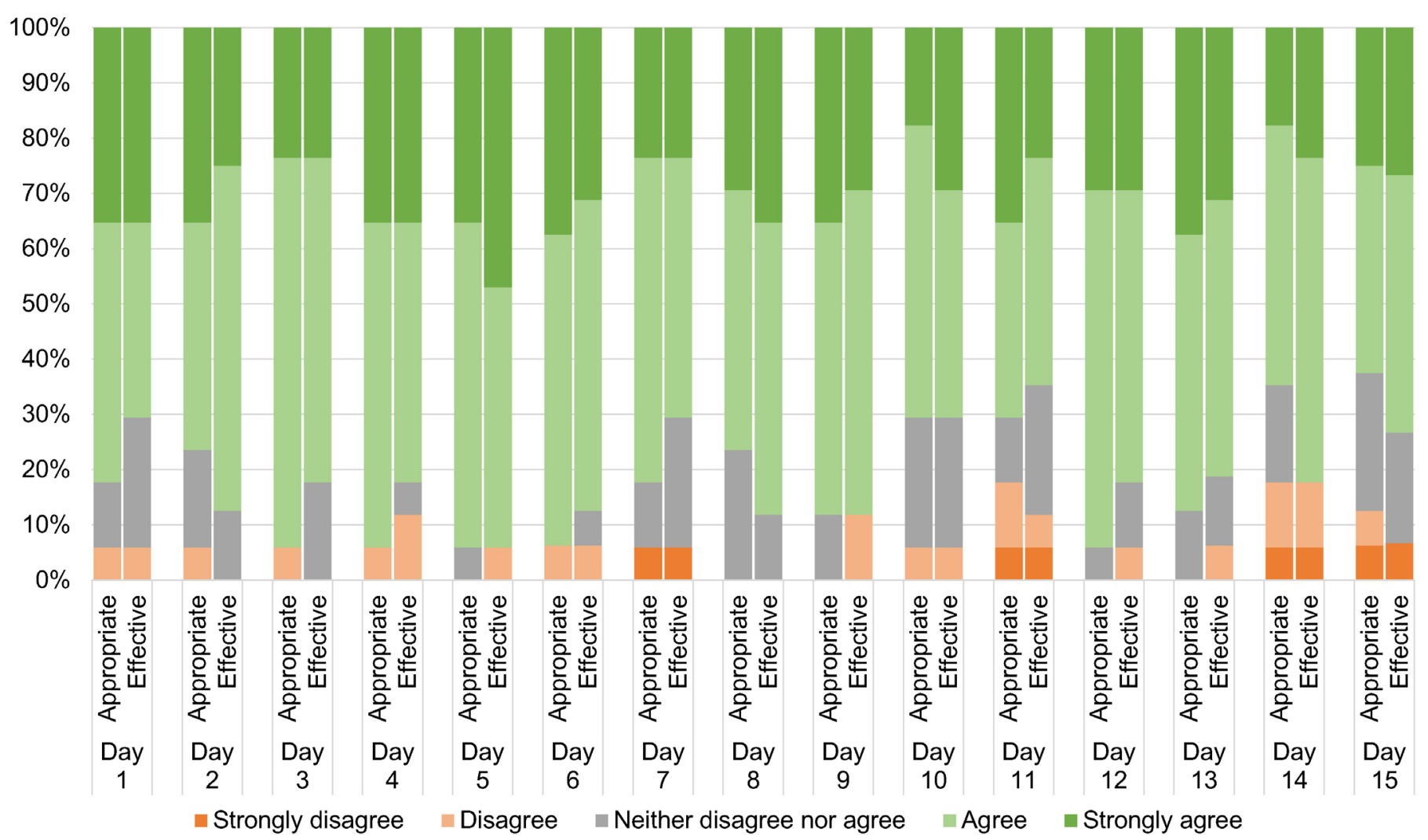

Figure 3. Percentage of teachers at each level of agreement to the prompts, "This model of instruction (guided Science Investigation, science-specific disciplinary literacy mini-lessons, and small group Science Inquiry Circle) is appropriate for my classroom," and "This model of instruction (guided Science Investigation, science-specific disciplinary literacy mini-lessons, and Science Inquiry Circle) was an effective approach to teaching the Day's ELA and science content to my students," for each activity day.

agreed that students were able to make these connections on most of the activity days (Figure 4). Day 2 and Day 12 were the days with the lowest percentage of teachers agreeing or strongly agreeing that students were able to apply the science to their small group Science Inquiry Circle work (53.3\% and $50.0 \%$ respectively). For Day 2 , teachers noted that students had difficulty with scientific language, constructing growth chambers (using plastic salad boxes), and working effectively in small groups. Additionally, one teacher felt that the hands-on Science Investigation was not aligned with the Science Inquiry Circle work on that day. For Day 12, three of the five teachers who did not agree that students were able to

Table 2. Examples of teacher comments regarding alignment among model components.

\begin{tabular}{|c|c|c|}
\hline $\begin{array}{l}\text { Activity } \\
\text { Day }\end{array}$ & Examples of Misalignment & Examples of Explicit Connections \\
\hline 3 & $\begin{array}{l}\text { "The use of magnifying lens is totally separate from the } \\
\text { small group inquiry circles." }\end{array}$ & $\begin{array}{l}\text { "In the same way we focus on an object, we can focus on a } \\
\text { particular question, make this connection in the lesson." }\end{array}$ \\
\hline 6 & $\begin{array}{l}\text { "The explanation in the guided science inquiry was ok, but } \\
\text { being able to apply this in small group inquiry, I could not } \\
\text { see this at this time, due to the fact that the activity was } \\
\text { more of an individual thing. Unless we are talking about the } \\
\text { understanding of the main idea." }\end{array}$ & $\mathrm{N} / \mathrm{A}$ \\
\hline 12 & $\begin{array}{l}\text { "The students were able to represent their data but I do not } \\
\text { think it was related to the Small Group Inquiry Circle. I } \\
\text { think it is a separate lesson in itself because the concepts } \\
\text { being taught are different." }\end{array}$ & $\begin{array}{l}\text { "As the students used measurement data from their previ- } \\
\text { ous lesson and learned a new skill of creating a line graph, } \\
\text { in the same context they used their inquiry charts to see } \\
\text { what they know about their organisms and used new skill } \\
\text { of creating a synthesis statement by adding something from } \\
\text { their own schema." }\end{array}$ \\
\hline 15 & $\begin{array}{l}\text { "I did not see how the guided science inquiry lesson could } \\
\text { be applied to the small group inquiry." }\end{array}$ & $\begin{array}{l}\text { "Information in this lesson handouts - dominant and reces- } \\
\text { sive traits and butterfly offspring physical traits was used to } \\
\text { sketch their organism's physical traits in both parents and } \\
\text { their offspring." }\end{array}$ \\
\hline
\end{tabular}


Activity Day 1 - Team Building for Scientific Research

Activity Day 2 - Constructing Larva Growth Chambers

Activity Day 3 - Making Things Appear Bigger

Activity Day 4 - Measuring Caterpillars

Activity Day 5 - Where Are the Caterpillars?

Activity Day 6 - Scientific Illustration

Activity Day 9 - Monarch Migration

Activity Day 10 - Inherited Butterfly Wing Characteristics 1

Activity Day 11 - Inherited Butterfly Wing Characteristics 2

Activity Day 12 - Caterpillar Growth Line Graph

Activity Day 13 - Famous Scientist

Activity Day 14 - Butterfly Offspring Part 1

Activity Day 15 - Butterfly Offspring Part 2

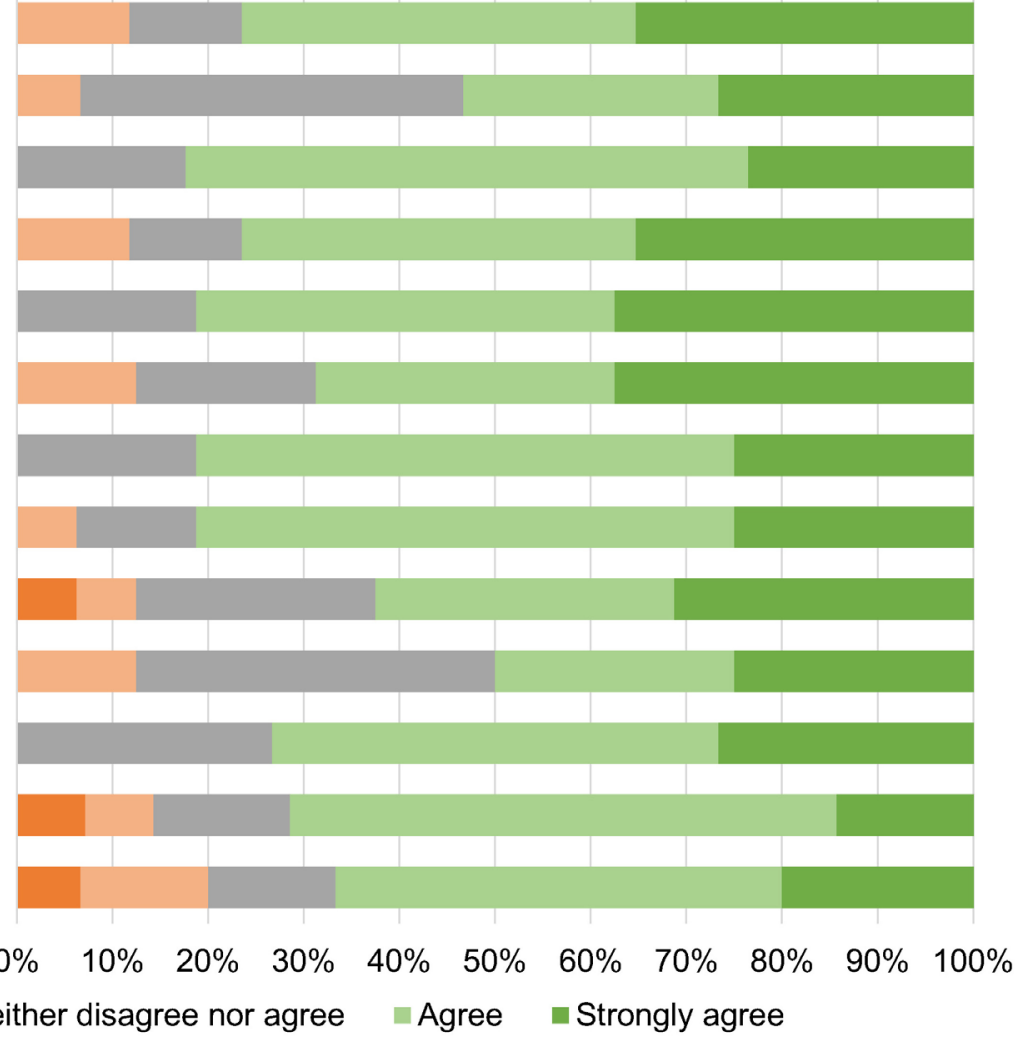

Figure 4. Percentage of teachers at each level of agreement to the prompt, "Students were able to apply the information from the guided Science Investigation to their work in the small group Science Inquiry Circles," for each activity day.

apply science knowledge to the small group work reported that students had difficulty creating line graphs. As with Day 2, one teacher indicated that the activities in these two sections of the model were not aligned.

Across all daily activity evaluation open-ended responses, four of the 18 teachers mentioned that they observed misalignment or lack of connection across the three model components, with at least one such comment on seven of the 15 activity days (Table 2). Days 6 and 15 had the most comments regarding alignment, with two each. However, Day 15 also received two comments in which other participants explicitly described the connections their students made.

When asked to consider the lessons as a unit, 78\% teachers agreed or strongly agreed that the set of activities in Heredity and Life Cycles were aligned and cohesive. The primary criticisms related to the unit were: 1) the need to differentiate both science and readings for varying levels of students, and 2) the difficulty of some of the science content, specifically the concepts and vocabulary related to days 14 and 15 which centered on inherited traits. Teachers also reported that the proposed teaching order of the three daily lessons (guided Science Investigations, science-specific disciplinary literacy Mini-lessons, and Science Inquiry Circle) did not parallel the usual sequence of activities in most elementary classrooms.
Alignment with NGSS Recommendations. Post-hoc, we compared the Heredity and Life Cycles unit against categories in the EQuIP Rubric (EQuIP, 2016), which is a tool designed to assess alignment of curricular materials with recommendations of the Next Generation Science Standards. Scores for various aspects of the unit within the three major rubric categories (Three-dimensional design, Instructional Supports and Monitoring Students Progress) are shown in Table 3. As noted, the pilot unit provides opportunities for learners to engage in the three dimensions of the NGSS, with the weakest area related to linkages across multiple science domains. Under Instructional Supports, guidance for differentiated instruction was flagged as an area not addressed by the instructions for teachers. Overall, Monitoring Student Progress was the weakest of the three rubric categories. As written, the unit has inadequate evidence of providing teachers with embedded formative assessments, guidance on using rubrics and or other scoring approaches, and conducting pre-formative, summative and self-assessment measures.

\section{Effectiveness of the Unit on Student Outcomes.}

Content Knowledge Assessments. Student summed total scores showed statistically significant increases from pre- to posttest on the 24 multiple-choice assessment (pre- $M=10.33$, pre $-S D=4.22$; post $-M=15.27$, post $-S D=5.06 ; t(300)=17.863$, $p<0.001$, Cohen's $d=1.064$ ) (Figure 4). While this outcome 
Table 3. Abbreviated Comparison of ALL for Science Module, Heredity and Life Cycles, to Categories of the EQuIP Rubric.

Three-dimensional Design: Designed so students make sense of phenomena and/or design solutions to problems by engaging in student performances that integrate the three dimensions of the NGSS.

\begin{tabular}{ll}
\hline Item Description & $\begin{array}{l}\text { Evidence } \\
\text { Present }\end{array}$ \\
\hline $\begin{array}{l}\text { Students explain phenomena or design } \\
\text { solutions to a problem }\end{array}$ & Extensive \\
\end{tabular}

All three dimensions present to enable Extensive sense-making

Integration of the Three Dimensions

Unit coherence

Links across multiple science domains

Links to Math and ELA
Instructional Supports: Supports three-dimensional teaching and learning for ALL students by placing the lesson in a sequence of learning for all three dimensions and providing support for teachers to engage all students.

Monitoring Student Progress: Supports monitoring student progress in all three dimensions of the NGSS as students make sense of phenomena and/or design solutions to problems.

to problems.

\begin{tabular}{l} 
Evidence \\
Present \\
\hline Extensive
\end{tabular}

Adequate Embeds formative assessment Inadequate processes throughout multiple formats.

Extensive Builds on prior knowledge in all Inadequate three dimensions

Extensive Scientifically accurate and grade-appropriate

Adequate

Provides rubrics and scoring Inadequate guidance for teachers

Assesses student proficiencies Adequate in ways that are accessible and unbiased

Includes pre-, formative, Inadequate summative, and self-assessment measures ated instruction

None

$\begin{array}{ll}\text { Extensive } & \text { Teacher support for unit coher- Adequate } \\ \text { ence }\end{array}$

Multiple opportunities for students to demonstrate learning and receive feedback

Evidence Present

Adequate

Scaffolded differentiation over Inadequate

time

is to be expected based on both the tight alignment of the assessment with the unit and the experience level of the pilot teachers, it was necessary for us to measure and assess student outcomes to gain understanding of the effectiveness of various lessons. A post-hoc analysis with a Bonferonni correction was applied to each of the individual items, so that effectiveness of various aspects of the unit could be examined more thoroughly (Table 4).

We took a closer look at the student outcomes in the classes of the 10 teachers (seven on the post-evaluation, and three on the activity evaluations) who wrote that the science concepts or vocabulary on days 14 and 15 (inherited traits activities) were "too advanced" for their learners. We explored student learning data and teacher reported information for systematic differences among classrooms that might impact teachers' perceptions of difficulty. First, we examined student scores on the pre/post assessment items directly related to this content area to determine whether students were successful in learning the vocabulary and concepts as measured. There were four items on the pre-/posttest that directly assessed this knowledge: two vocabulary matching items, and two multiple choice questions (Figure 5). When compared to peers whose teachers did not voice a concern about the conceptual difficulty of the materials, students whose teachers had a concern about the difficulty level had statistically equivalent or significantly higher gains on all four items (Table 5).
In most cases, the students whose teachers expressed concern at the difficulty level had slightly lower pretest scores on the inherited traits items, though their average scores were close to peers by the posttest. The teachers who expressed that the content was too advanced reported a greater proportion of students considered to be performing below grade level in both science (too advanced: $42 \%$ vs. no mention: $30 \%$ ) and ELA (too advanced: $52 \%$ vs. no mention: $31 \%$ ), while those who did not express concern had a higher proportion of ELL students in their classrooms (46\% compared to $30 \%$ ).

\section{DISCUSSION}

The pilot of the ALL for Science three-component curriculum framework, which combines science-specific literacy strategies and skills development, with firsthand science investigations, yielded student knowledge gains and teacher reported data in support of the approach - as implemented in the context of heredity and animal life cycles for second grade students. Inclusion of science-specific disciplinary literacy strategies in elementary education has many potential benefits, including linkage to other standards or Common Core requirements, development of students' sense-making thinking skills and exposure to discourse and argument (NRC, 2014). However, there are a number of barriers to implementation, such as lack of appropriate free curricular 
Table 4. Descriptive statistics and post-hoc paired t-test with Bonferonni correction analyses for individual assessment items.

\begin{tabular}{|c|c|c|c|c|c|c|c|c|}
\hline \multirow{2}{*}{ Item \# } & \multirow{2}{*}{ Item } & \multirow{2}{*}{$N$} & \multicolumn{2}{|c|}{ Pretest } & \multicolumn{2}{|c|}{ Posttest } & \multirow{2}{*}{ change } & \multirow{2}{*}{$p$} \\
\hline & & & $M$ & $S D$ & $M$ & $S D$ & & \\
\hline \multirow[t]{4}{*}{1} & Roles - Principal investigator & 281 & 0.24 & 0.43 & 0.63 & 0.48 & $0.39 *$ & 0.000 \\
\hline & Roles - Maintenance Director & 270 & 0.23 & 0.42 & 0.57 & 0.50 & $0.34 *$ & 0.000 \\
\hline & Roles - Reporter & 277 & 0.53 & 0.50 & 0.66 & 0.48 & $0.13 *$ & 0.001 \\
\hline & Roles - Materials Manager & 277 & 0.51 & 0.50 & 0.74 & 0.44 & $0.23 *$ & 0.000 \\
\hline \multirow[t]{6}{*}{2} & Vocabulary - Inherited Traits & 215 & 0.40 & 0.49 & 0.60 & 0.49 & $0.20 *$ & 0.000 \\
\hline & Vocabulary - Migrate & 267 & 0.54 & 0.50 & 0.74 & 0.44 & $0.21 *$ & 0.000 \\
\hline & Vocabulary - Larva & 269 & 0.65 & 0.48 & 0.83 & 0.37 & $0.19^{*}$ & 0.000 \\
\hline & Vocabulary - Recessive & 225 & 0.36 & 0.48 & 0.57 & 0.50 & $0.22 *$ & 0.000 \\
\hline & Vocabulary - Life Cycle & 267 & 0.55 & 0.50 & 0.73 & 0.45 & $0.18 *$ & 0.000 \\
\hline & Vocabulary - Observations & 260 & 0.40 & 0.49 & 0.57 & 0.50 & $0.17 *$ & 0.000 \\
\hline 3 & $\begin{array}{l}\text { A team of scientists measures a caterpillar every day for a week, and } \\
\text { makes a graph with all of the measurements. Fill in the bubble above the } \\
\text { best prediction for the pattern they will see on the graph }\end{array}$ & 274 & 0.24 & 0.43 & 0.68 & 0.47 & $0.44 *$ & 0.000 \\
\hline 4 & How many wings does a butterfly have? & 287 & 0.31 & 0.46 & 0.54 & 0.50 & $0.23 *$ & 0.000 \\
\hline 5 & $\begin{array}{l}\text { Which of the following sentence stems might scientist use BEFORE doing } \\
\text { an experiment? }\end{array}$ & 295 & 0.43 & 0.50 & 0.66 & 0.48 & $0.22 *$ & 0.000 \\
\hline 6 & $\begin{array}{l}\text { Which of the following sentence stems might a scientist ask AFTER doing } \\
\text { an experiment? }\end{array}$ & 297 & 0.28 & 0.45 & 0.46 & 0.50 & $0.18^{*}$ & 0.000 \\
\hline 7 & What Is the order of the life cycle of a butterfly? & 298 & 0.69 & 0.46 & 0.87 & 0.33 & $0.18^{*}$ & 0.000 \\
\hline 8 & What affects monarch butterfly migration the most? & 295 & 0.49 & 0.50 & 0.64 & 0.48 & $0.16^{*}$ & 0.000 \\
\hline 9 & $\begin{array}{l}\text { Which tool would be most helpful in observing the features of butterfly } \\
\text { wings? }\end{array}$ & 293 & 0.58 & 0.49 & 0.77 & 0.42 & $0.19 *$ & 0.000 \\
\hline 10 & What are offspring? & 299 & 0.25 & 0.43 & 0.58 & 0.49 & $0.33 *$ & 0.000 \\
\hline 11 & What are genes? & 294 & 0.40 & 0.49 & 0.67 & 0.47 & $0.27 *$ & 0.000 \\
\hline 12 & What should you never look at with a magnifying glass? & 293 & 0.31 & 0.46 & 0.51 & 0.50 & $0.19 *$ & 0.000 \\
\hline 13 & $\begin{array}{l}\text { For how many days do the butterfly larva eat and grow before they form } \\
\text { chrysalises? }\end{array}$ & 297 & 0.45 & 0.50 & 0.53 & 0.50 & 0.08 & 0.026 \\
\hline 14 & What happens inside a chrysalis? & 294 & 0.60 & 0.49 & 0.73 & 0.44 & $0.13 *$ & 0.000 \\
\hline 15 & Which would be a good title for this paragraph? & 299 & 0.61 & 0.49 & 0.75 & 0.43 & $0.14 *$ & 0.000 \\
\hline 18 & What can you conclude about the armor of armadillos? & 289 & 0.79 & 0.41 & 0.81 & 0.40 & 0.02 & 0.486 \\
\hline
\end{tabular}

$*=p<0.05$ with Bonferroni correction for multiple comparisons

resources and models for how teachers can integrate the development of discipline-specific literacies. Our goal was to develop an instructional model that would enable teachers to easily and authentically engage students in learning and applying science-specific disciplinary literacy approaches in the early elementary classroom setting.

From a pragmatic standpoint, teachers were able to put the model into practice, follow the instructions, and conduct the activities with students over the course of an entire threeweek unit. This finding is not trivial, given that the model has three distinct instructional components. It is notable, however, that teachers selected for the curriculum pilot had prior experience with leading students in hands-on science activities. It will be important to learn whether teachers with little science teaching experience (and/or teachers who are reticent to teach science) are able to use components based on the ALL for Science curriculum framework successfully.
In addition, for the pilot, we removed typical barriers that teachers face when conducting hands-on science activities by providing all hands-on materials and hard/digital copies of needed materials.

The mismatch between the teaching order of the three framework components (beginning with science and ending with reading) and the usual sequence of activities in most elementary classrooms was notable and could represent a barrier to implementation. Typically, reading is taught in the morning and science activities, when taught, occur in the afternoon. Accordingly, this and future units developed using the ALL for Science curriculum framework will begin with the science-specific disciplinary literacy Mini-lessons, followed by Science Inquiry Circles and ending with hands-on Science Investigations.

As noted by teachers, the Heredity and Life Cycles unit did not connect the goals and activities conducted by stu- 


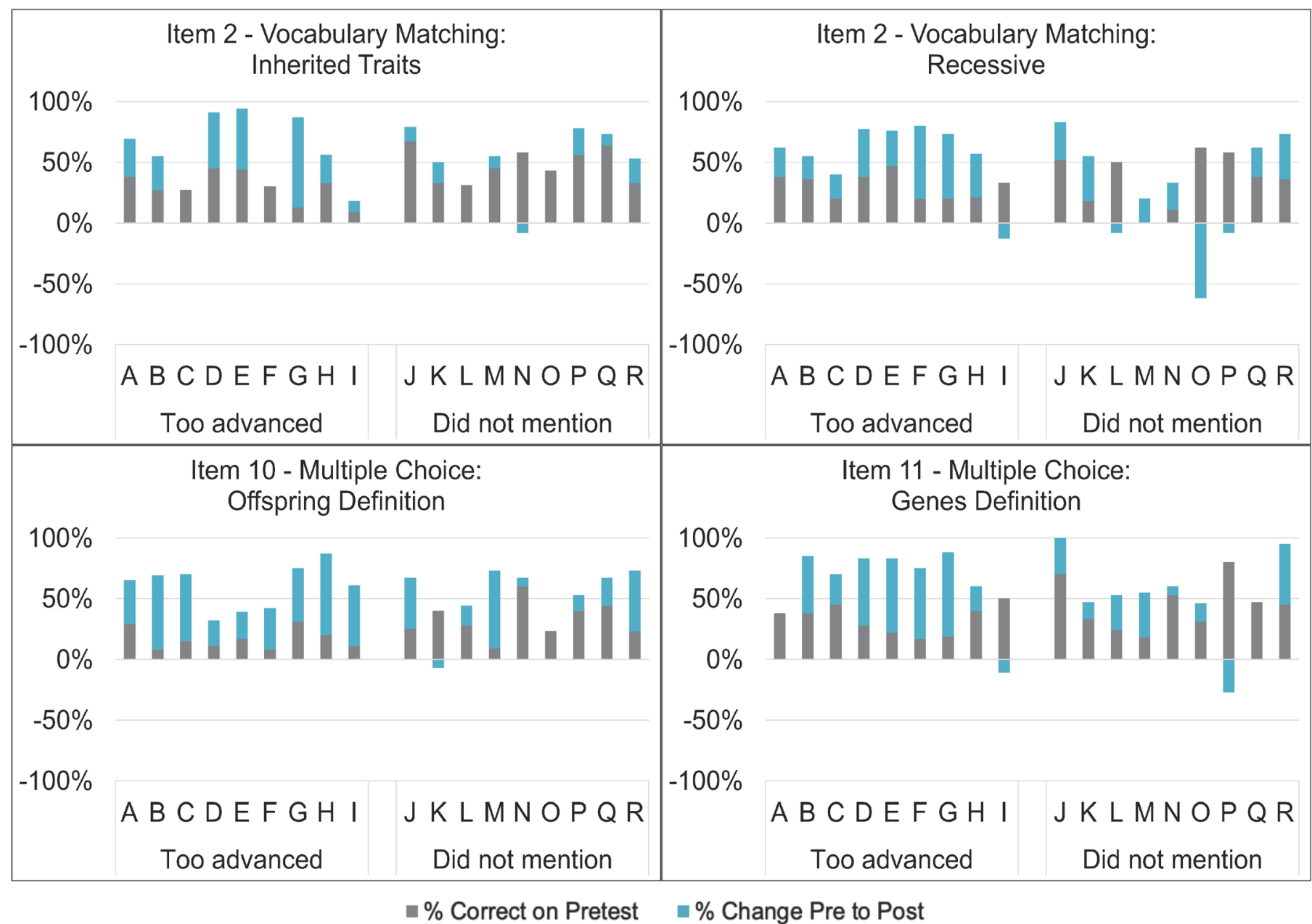

Figure 5. Percent of students in each classroom who answered each of the four inherited traits items correctly on the pretest and change in percent of students answering correctly on posttest grouped by teachers' perceptions of concept difficulty.

dents across the three-unit components on some days. These connections can be made more explicit in revisions to the current unit and in subsequent units developed for other grade levels by re-ordering some of the ELA mini-lessons and by providing more guidance to teachers about how to manage transitions across the three types of activities.

The retrospective comparison of the unit to categories in the EQuIP Rubric point to a need to design and include explicit formative and summative assessments for teachers to use with students. For this initial pilot, we relied on teachers to use student artifacts (such as science notebooks, observation sheets, or group work in the Science Inquiry Circles) to assess student progress and provide feedback. Since we had recruited an experienced group of teachers, the lack of formal assessment tools did not seem to present any challenges to implementation of the framework. However, if the framework is to be implemented with less experienced science teachers, a revised version of the current unit (and of the model itself) will need to include assessment strategies and tools, such as rubrics for student writing. Similarly, explicit attention will need to be paid to providing strategies on how to differentiate instruction among students with vary- ing needs within the context of the model. As an aside, it is important to clarify that student writing samples are being examined as a companion study to the results reported here.

The science inquiry-based activities (Science Investigations) related to life cycles and inheritance based on painted lady butterflies overall were viewed by teachers as appropriate for second grade students. However, the heredity activities at the end of the unit sequence were viewed as too difficult for students by nine of the 18 teachers. These activities challenged students to come up with basic understandings of inherited traits, based on observations of wing patterns in parent and offspring butterflies. The nine teachers who had concerns about instructional level reported greater percentages of students performing below grade level in their classes (Below grade in ELA: too advanced $=44 \%$; did not mention $=28 \%$; below grade in science: too advanced $=36 \%$; did not mention $=24 \%$ - full table in Appendix). However, analysis of student pre-posttest scores revealed that students in those classes scored similarly on posttests of related content knowledge as students in classes of other teachers, who did not report similar concerns. From a curriculum evaluation perspective, it appears that the content and lesson design 
Table 5. Comparison of student outcomes on inherited traits items between teachers who felt the content was too difficult and those who did not express the sentiment

\begin{tabular}{|c|c|c|c|c|c|}
\hline \multicolumn{6}{|c|}{ Vocabulary Matching - Inherited Traits } \\
\hline & Pre- $M$ & Pre- $S D$ & Post- $M$ & Post-SD & Gain \\
\hline Too advanced & 0.28 & 0.45 & 0.61 & 0.49 & $0.32 *$ \\
\hline Did not mention & 0.45 & 0.50 & 0.59 & 0.49 & 0.09 \\
\hline \multicolumn{6}{|c|}{ Vocabulary Matching - Recessive } \\
\hline & Pre- $M$ & Pre- $S D$ & Post- $M$ & Post-SD & Gain \\
\hline Too advanced & 0.33 & 0.47 & 0.62 & 0.49 & 0.29 \\
\hline Did not mention & 0.39 & 0.49 & 0.54 & 0.50 & 0.13 \\
\hline \multicolumn{6}{|c|}{ Multiple Choice - What are offspring? } \\
\hline & Pre- $M$ & Pre- $S D$ & Post- $M$ & Post-SD & Gain \\
\hline Too advanced & 0.17 & 0.38 & 0.60 & 0.49 & 0.43 \\
\hline Did not mention & 0.36 & 0.48 & 0.57 & 0.50 & 0.25 \\
\hline \multicolumn{6}{|c|}{ Multiple Choice - What are genes? } \\
\hline & Pre- $M$ & Pre- $S D$ & Post- $M$ & Post-SD & Gain \\
\hline Too advanced & 0.34 & 0.47 & 0.67 & 0.47 & 0.35 \\
\hline Did not mention & 0.47 & 0.50 & 0.66 & 0.48 & 0.19 \\
\hline
\end{tabular}

are suitable for students with differing levels of preparation in reading or science, even in the absence of explicit instructions on how to offer differentiated instruction. This finding has significance for dissemination of the current unit once revised and further refinement of the curriculum framework. The finding also suggests that the ALL for Science curriculum framework might help mitigate teachers' concerns about having to address complex science topics outside their own areas of science expertise (Cronin-Jones, 1991; Mansour 2009).Teachers levels of comfort with both the science content and science-specific literacy strategies will be important themes to examine in subsequent evaluations of the model with other topics and grade levels.

Importantly, the students in this pilot study (considered very young by many standards) were able to engage in practices that are much closer to how scientists work than students would experience otherwise. Each day, students worked with an example live organism (painted lady butterfly) and then consulted existing expository text resources to answer questions and extend their knowledge to another organism. Using peer-reviewed literature sources is an ongoing, iterative process for all scientists. Consulting with other sources enables investigators to build on existing knowledge, make use of accumulated knowledge and generate new questions (Egger and Carpi, 2009). The second-grade students in the ALL for Science pilot did not consult primary, peer-reviewed literature, but their usage of expository text and media was closer to authentic scientific practices than typically occurs in science classrooms in the early grades.

The observed improvements in students' science content knowledge, and teacher reported improvements in students' abilities to learn relevant reading strategies and apply find- ings from science investigations to their inquiry circle work are aligned with positive findings related to kindergartner's use of science talk (such as making claims, using evidence or using vocabulary in a science context) (Wright and Gotwals, 2017). Shanahan and Shanahan (2014) argue that disciplinary literacy (in any field) prepares elementary students for more advanced work in middle and high school, where they will be expected to use a wide range of informational texts, handle specialized vocabulary and compare information across different sources.

It is notable that students demonstrated gains across all of the items on the knowledge assessment. The greatest gain pre/post was shown on item 3 related to students' firsthand experience over multiple days in measuring and recording the lengths of painted lady butterflies. The item is directly related to the NGSS crosscutting concept of patterns. This limited finding supports the value of engaging students firsthand in scientific investigations in order to build understandings of how scientists view the world.

Students demonstrated large gains in knowledge about the meaning of genetics-related terminology, such as offspring, genes and recessive (items 2, 10,11), even though some teachers flagged this topic as too difficult for students in second grade. Students also improved on items related to ways in which scientists speak about their investigations (items 5 and 6). In combination, these outcomes make a case for continuing to explore how reading, writing and speaking as scientists support the development of content knowledge in concert with disciplinary literacies. While we didn't set out to study the theory that guided our work, our findings may indicate that a well-thought out curriculum framework that operates from a theoretical perspective, may offer affordances to students that a standards-driven curriculum cannot, especially when it comes to folding students into the practice of science by recognizing and acknowledging their interests and operating away from the false dichotomy of academic language vs home language/ lived experiences of children (Flores, 2020).

Science-specific disciplinary literacy practices are becoming more frequent at the higher grades, but are less typical in grades K-3 (NRC, 2014). It is possible that such practices may positively influence students' science attitudes and identities at an early age and contribute to long term persistence in science pathways. Thus, creating a feasible framework for teachers or curriculum developers to put into practice without having access to curricula with customized reading materials represents an alternative approach to developing students' disciplinary literacy in the context of science.

Implications for Future Curriculum Development Using the ALL for Science Model. The ALL for Science curriculum framework with its three components to develop knowl- 
edge and skills in all three dimensions of the NGSS along with development of science-specific disciplinary literacies represents a different approach to integrating elementary science teaching and ELA teaching. Although there are three distinct aspects of the model - firsthand Science Investigations, science-specific disciplinary literacy Mini-lessons, Science Inquiry Circles - for the purpose of this investigation, they were viewed and evaluated holistically, in an effort to identify if the model overall was successful in helping apply authentic science practices related to disciplinary literacy in early elementary classrooms. Future applications of the model may investigate the additive effect of the three components to further identify best practices in implementing such activities in these settings.

It is notable that the curriculum development process for the first unit was intensive and multidisciplinary. The development team included educators, curriculum designers and science professionals, and the process was structured and intentional in order to ensure that the content for both science and ELA were aligned, not only with each other, but also with state and local standards. Even with these efforts, the three components of the model were viewed as effective by pilot test teachers in a life science context.

Further, in order to build a classroom community of practice, the local environment must be considered, so that students are exposed to topics that require coverage, as well as materials and activities that are accessible and understandable. In the case of the current unit, although our state did not adopt NGSS, the content was selected to fit state standards while being mindful of the overlap with the national guidelines. New units developed using the model should similarly be mindful of context, and strive to incorporate flexibility into unit designs. Further work also is necessary to determine whether outcomes from this and future studies of the framework generate evidence regarding development of students' identities as members of a community of scientific practice.

Finally, an element of professional development may be needed to support teachers who wish to implement the ALL for Science model in their classrooms. Many teachers in early elementary struggle to implement science activities, and may lack knowledge of the authentic work of scientists, particularly in terms of their use of language. Thus, both contextual and pedagogical support for teachers must be explicitly included with any curriculum based on the model of instruction.

\section{CONCLUSION}

The ALL for Science curriculum framework was designed to engage students in authentic science practices and skills, specifically those related to language, in a novel way that supports development of science knowledge and skills and science-specific disciplinary literacies. A pilot of the framework based on the life science topic of heredity and animal life cycles was successful in promoting gains in students' related content knowledge and literacies. The model was evaluated positively by teachers who taught using the framework over a three-work period of time. Feedback from teachers provided insights into how to improve the framework and specific unit for future implementation. Future work also will examine whether the model supports students' feelings of inclusion in the scientific community of practice.

\section{ASSOCIATED CONTENT}

Supplemental material mentioned in this manuscript can be found uploaded to the same webpage as this the manuscript.

\section{AUTHOR INFORMATION Corresponding Author}

Alana Newell, Center for Educational Outreach, Baylor College of Medicine, 1 Baylor Plaza, MS:BCM411. Email: adnewell@bcm.edu

\section{Author Contributions}

The manuscript was written through contributions of all authors. All authors have given approval to the final version of the manuscript.

\section{ACKNOWLEDGMENTS}

We dedicate this manuscript to health and science educator, William Thomson, founding director and visionary architect of the Center for Educational Outreach at Baylor College of Medicine, and designer Martha Young, whose dedication to our team and this project was unparalleled. We also thank Sarah Aguirre, Janine Garcia, and Gregory Vogt for their extraordinary efforts to develop, refine and implement the science and literacy lessons, Travis Kelleher for developing and maintaining the website, and James Denk for reviewing and editing various written components. We are especially appreciative of our collaborating teachers and students in both Houston and San Antonio who participated in the pilot program.

\section{FUNDING SOURCES}

Research reported here was supported by the National Institute of General Medical Sciences of the National Institutes of Health under Award Number R25GM129204 administered through the Science Education Partnership Award program. The content is solely the responsibility of the authors 
and does not necessarily represent the official views of the National Institutes of Health.

\section{ABBREVIATIONS}

ALL: Authentic Literacy and Language; CCSSI: Common Core State Standards Initiative; ELA: English Language Arts; EQuIP: Educators Evaluating the Quality of Instructional Products; NGSS: Next Generation Science Standards; STEM: Science, Technology, Engineering, and Mathematics

\section{REFERENCES}

Archer, L., DeWitt, J., Osborne, J., Dillon, J., Willis, B., and Wong, B. (2010). "Doing" science versus "being" a scientist: Examining 10/11-year-old schoolchildren's constructions of science through the lens of identity. Science Education, 94(4), 617-639.

Ashbrook, P. (2016). Science Learning in the Early Years: Activities for PreK-2. Arlington, VA: NSTA Press, National Science Teachers Association.

Buehl, D. (2017). Developing Readers in the Academic Disciplines. Stenhouse Publishers.

Carlone, H., Scott, C., and Lowder, C. (2014). Becoming (less) scientific: A longitudinal study of students' identity work from elementary to middle school science. Journal of Research in Science Teaching, 51(7), 836-869.

Cervetti, G., Barber, J., Dorph, R., Pearson, P., and Goldschmidt, P. (2012). The impact of an integrated approach to science and literacy in elementary school classrooms. Journal of Research in Science Teaching, 49, 631-658.

Cronin-Jones, L. L. (1991). Science teacher beliefs and their influence on curriculum implementation: Two case studies. Journal of Research in Science Teaching, 28(3), 235-250.

[CCSSI] Common Core State Standards Initiative. (2020). English Language Arts Standards: Grade 2. Accessed online, May 28, 2020 http:/www.corestandards.org/ELA-Literacy/ $\mathrm{SL} / 2 /$

Educators Evaluating the Quality of Instructional Products (EQuIP) Rubric (2016). EQuIP Rubric for Lessons and Units: Science, Version 3.0. Accessed online, April 15, 2020, https:// www.nextgenscience.org/resources/equip-rubric-science.

Edson, M. (2013). Starting with Science: Strategies for Introducing Young Children to Inquiry. US: Stenhouse Publishers.

Egger, A. E., and Carpi, A. (2009). Scientific communication: utilizing the scientific literature. Visionlearning, (7).

Flores, N. (2020). From academic language to language architecture: Challenging raciolinguistic ideologies in research and practice, Theory into Practice, 59(1), 22-31, DOI: 10.1080/00405841.2019.1665411
Gavelek, J., and Bresnahan, P. (2009). Ways of making meaning: Sociocultural perspectives on reading comprehension. In S. E. Israel and G. G. Duffy (Eds.), Handbook of Research on Reading Comprehension (pp. 140-176). Routledge.

Goldhaber, D., Lavery, L., and Theobald, R. (2015). Uneven playing field? Assessing the teacher quality gap between advantaged and disadvantaged students. Educational Researcher, 44(5), 293-307.

Hayes, S. (2017). Preparation Matters Most in STEM. ACT Research and Policy. Policy Brief. ACT, Inc. Accessed online, March 4 2020, https://eric.ed.gov/?id=ED581673

Houseal, A., Gillis, V., Helmsing, M., and Hutchison, L. (2016). Disciplinary literacy through the lens of the next generation science standards. Journal of Adolescent and Adult Literacy, 59(4), 377-384.

Knowlton, L. and Phillips, C. (2012). The Logic Model Guidebook: Better Strategies for Great Results. Sage Publications, Inc.

Lave, J., and Wenger, E. (1991). Situated learning: Legitimate peripheral participation. Cambridge University Press.

Lee, C. D., and Goldman, S. R. (2015). Assessing literary reasoning: Text and task complexities. Theory into Practice, 54(3), 213-227.

Mansour, N. (2009). Science teachers' beliefs and practices: Issues, implications and research agenda. International Journal of Environmental and Science Education, 4(1), 25-48.

National Academies of Sciences, Engineering, and Medicine. (2016). Science Literacy: Concepts, Contexts, and Consequences. Washington, DC: The National Academies Press. doi:10.17226/23595.

National Research Council. (2011). Successful K-12 STEM education: Identifying effective approaches in science, technology, engineering, and mathematics. National Academies Press.

National Research Council. (2012). A Framework for K-12 Science Education: Practices, Crosscutting Concepts, and Core Ideas. Committee on a Conceptual Framework for New K-12 Science Education Standards. Board on Science Education, Division of Behavioral and Social Sciences and Education. Washington, DC: The National Academies Press.

National Research Council. (2014). Literacy for Science: Exploring the Intersection of the Next Generation Science Standards and Common Core for ELA Standards: A Workshop Summary. Washington, DC: The National Academies Press. https://doi.org/10.17226/18803.

National Research Council. (2015). Guide to implementing the next generation science standards. National Academies Press.

NGSS Lead States. (2013). Next Generation Science Standards: For states, by states. Washington, DC: The National Academies Press. 
Pearson, P., Moje, E., and Greenleaf, C. (2010). Literacy and science: Each in the service of the other. Science, 328(5977), 459-463.

Shanahan, C., \& Shanahan, T. (2014). Does disciplinary literacy have a place in elementary school?. The Reading Teacher, 67(8), 636-639.

Shanahan, C., Shanahan, T., and Misischia, C. (2011). Analysis of expert readers in three disciplines: History, mathematics, and chemistry. Journal of Literacy Research, 43(4), 393429.

Shanahan, T., and Shanahan, C. (2012). What is disciplinary literacy and why does it matter?. Topics in Language Disorders, 32(1), 7-18.

Wiggins, G., and McTighe, J. (2005). Understanding by Design. Alexandria, VA: ASCD Press.

Vincent-Ruz, P., and Schunn, C. D. (2018). The nature of science identity and its role as the driver of student choices. International Journal of STEM education, 5(1), 48.

Wright, T., and Gotwals, A. (2017). Supporting Kindergartners' Science Talk in the Context of an Integrated Science and Disciplinary Literacy Curriculum, The Elementary School Journal 117(3), 513-537. https://doi.org/10.1086/690273

Zhai, J., Jocz, J. A., and Tan, A. L. (2014). 'Am I Like a Scientist?': Primary children's images of doing science in school. International Journal of Science Education, 36(4), 553-576. 